\title{
Strategy in A Digitally Disrupted Environment
}

\author{
Dr. Sean Stein Smith, \\ Institute of Management Accountants
}

\section{Introduction}

Strategy and strategic planning are essential for the long-term success of organizations, regardless of industry, or whether the organization is profit driven or mission oriented. Charting the course for the organization requires a broad base of inputs sources as well as incorporating the needs of end users within the decision making process. Planning for the long-term, however, is critically dependent on the following reality. All organizations must produce more resources through operational activities than are consumed by those same operational activities. If this situation fails to occur, the entity will not remain in business for long. Stated differently, in order to successfully plan and execute long term strategies at an organizational level, it is imperative that management professionals implement and execute short-term objectives consistently.

This dynamic and struggle between short term objectives and longer term plans ascended to prominence following the financial crisis of 2007-2008. In the aftermath of financial turbulence felt on a global scale, management professionals faced a simultaneous and somewhat conflicting dual mandate from shareholders and other stakeholders. First, stabilization of financial performance and a return to profitable growth were a primary focus of financial shareholders. Management teams responded accordingly by increasing productivity, reducing capital investment in many industries, implementing increasingly selective hiring policies, and in some cases, introducing a reduction in product size without corresponding reductions in price. Second, and arguably more interesting within the framework of strategic thinking and execution, are the increasing demands on non-financial stakeholders for organizational information. This fundamental change in the context of communication between organizations and end users forms the foundation of the changing nature of strategic planning and decision making.

\section{Redefining Strategy}

Strategy has long been characterized and classified by the linkage between strategy and financial performance; Robert Kaplan and Michael Porter established theories that guide decision making processes through the present. The foundations of both approaches acknowledge the reality that strategy is not a single event or decision making process, but a combination of forces internal and external to the organization that influences management decision making. Strategy, based on the numerous headline-driven stories in the market, is in need of a rethinking in light of the changing market dynamics that are influencing business decision making. One example of this change are opportunities for value creation in non-traditional areas such as sustainability (Lampikoski, Westerlund, Rajala\&Molle, 2014). Specifically, strategy and strategic planning must serve a role in readdressing the balance between shorter-term execution and long-term stewardship and growth of organizational assets, such as the opportunity presented by meshing sustainability with increased financial performance.

This much is widely agreed upon; strategy and strategic planning require management professionals to embrace a longer term orientation and perspective asthey pertain to decision making. Against this, however, is the pressure to improve short-term performance and execution. Regardless of whether the entity is publicly traded or privately held, the same sets of pressures and expectations apply - to increase financial returns consistently from period to period. Strategy, in its current form, is too often relegated to a supporting role or a concept that is not periodically updated in response to changing market conditions. Strategic plans and initiatives are presented and approved, but if information changes, the plan is often not flexible enough to incorporate such changes.

\section{Data and Strategic Thinking}

Data is the life blood of business decision making, and drives the vast majority of decisions undertaken by business enterprises of all sizes and in all industries, but the nature and quantity of organizational information have evolved significantly in recent decades. Increased points of contact between organizations and customers are evident in the interaction between companies and customers on social media in real time. Social media has created a very interesting effect. Akin to crowdfunding, democratizing the process by which organizations raise capital to expand and launch new projects, social media allows customers and other stakeholders to crowdfund information (Laurell\&Sandstrom, 2014). Real time feedback and information from customers and clientele are 
invaluable, as organizations refine and possibly reorient specific product and service lines in response to customer feedback.

This information, while applicable to tactical product decision making, should also be integrated into the strategic and longer term decision making process. The finance function, spanning the chief financial officer to staff level professionals,is increasingly involved with technology applications. Specifically, it is important to link the data gathered from various systems to business problems, and to leverage this information to formulate and distribute business solutions (Morio, 2014). The data available to organizations includes both qualitative and quantitative information, and while quantitative (often financial data) is a primary focus of management professionals, it is also important for entities to be able toquantifyqualitative information as well. Additionally, and more importantly for management decision makers, are the evolution and increase in information available to business from internal operations and processes

\section{Quantifying the Qualitative}

Qualitative information provides a relevant context for business decision making, but it has traditionally been limited to merely providing a narrative around the underling quantitative information. Ideas such as disruptive innovation, blue ocean strategy, and fast follower innovation are the focus of academic articles and occasional article columns, but the integration of such concepts into decision making remains limited. This represents an opportunity for business professionals to address an important need within the marketplace. Many, if not all, of the theories underpinning strategic thinking and strategy implementation require an integration and blending of qualitative and quantitative information. Technology, however, simultaneously presents a tremendous opportunity for decision makers, as well as a challenge in terms of adaptability and organizational learning.

Stated in a slightly different manner, it is clear that merely analyzing the financial performance, or specific operational data generated by the organization, is insufficient. The rate at which an organization can adapt to technological evolution is a key aspect of developing an environment conducive to innovation. That said, traditional corporate structures and hierarchy that foster productivity and organizational efficiency can, in effect, limit the pace at which technology can be adapted (Hamada, 2014). A broader lens, perhaps the proverbial big picture,is required in order to effectively plan and execute strategy in a globalized and increasingly competitive global economy. In order to effectively integrate strategic thinking and theoretical constructs into actionable business decision making, there is one other aspect required in the modern business landscape, i.e., the reality of ramifications of multi-platform business models.

\section{Multi-Platform Business Models}

The concept of engaging customers on multiple platforms through multiple methods of communication has long been a goal of retailers and other customer-focused industries. Establishing online platforms, increasing social media engagement, and interacting with non-financial stakeholders on a continuous basis are routinely the norm for management decision making. Multi-platform business models, virtually by default, create a managerial situation akin to a portfolio situation, i.e., the strategies individual components must be aligned with the strategy of the business at large (Uggla, 2015). Examples such as Amazon, operating a wide variety of business lines, provide a market demonstration of how such a concept is realized within the marketplace. Besides the operational requirements to effect such changes in how the business model operates and conducts routine business transactions, it is also important to link the idea of multi-platform business operations to strategic thinking and strategic planning.

Network effects, in essence, represent a uniquely positive environment to foster disruptive innovation via collaboration between different aspects of the organization that participate in the network (Gawer\&Cusumano, 2014). Organizations such as Amazon have shown how multiple business platforms can readily utilize information gathered from one platform to fulfill business needs in other platforms. The evolution of Amazon from online book seller to fully-integrated online retailer and content producer has, in large part, been a result of strategic thinking. It is simple to think that such a concept, multiple platforms and business operations, is only applicable to technology-based organizations. This, however, provides an incomplete view of how strategy and strategic thinking works and is applicable to business decision making. Every organization engages with customers, shareholders, and stakeholders on multiple platforms.It is merely a question of linking existing actions to underlying theories of strategic thinking and strategic planning.

\section{Strategic Planning Theory: Applications}

It is critical, when analyzing the concepts of strategic thinking and innovation, to understand that there are a variety of options available to management decision makers. Actualizing theories, including the ones that pertain to strategic planning and thinking, is not necessarily a straightforward task. Analyzed previously within this article, there is a constant struggle between the short-term pressures of the marketplace, including those 
applied by shareholders, and the longer-term goals of stakeholders. Balancing these sometimes conflicting objectives is a requirement of management professionals, and an underlying goal of strategic theory as well as of the strategic planning process. Depending on the industry and specific organization, clearly there will be different applications and ideas that work best for the organization in question. The task of management professionals is to examine and analyze the information available to make the most effective decision for their organization.

\section{Disruptive Innovation}

Disruptive innovation, introduced and communicated by Clayton Christensen of Harvard University, represents perhaps the most oft-cited theory of innovation by market professionals. The underlying features of disruptive innovation center around a new product or service entering the marketplace that disrupts or upends the traditional organizations offering similar products. Characteristics of disruptive innovation often include the reality that the new disruptive service or product debuts at a lower price point than existing offerings. Linked with fewer features, this lower price appeals to a certain set of users that are willing to trade features for a lower price point. Over time, and leveraging the customer familiarity, information, and product trust gained earlier in the product cycle, the disruptive innovator eventually climbs the value chain. Stated in a slightly different manner, sometimes in order to innovate successfully in a rapidly shifting business landscape, the very business model of the organization must evolve alongside innovation embedded into operational decision making (Schnedider\& Spieth, 2014). At a certain point, the disruptive organization dethrones the reigning market leader, and takes lead position in the marketplace. Recent examples of such a transition might be include Netflix and Blockbuster. Looking back, the rise of Netflix and fall of Blockbuster seem assured, but that is the power of hindsight - strategic planning and a long term focus are what enabled such a transition to occur.

That said, it is important to realize that disruptive innovative in a digital environment follows a similar, but not exact, path to the disruption curve outlined above. In the digital landscape within which organizations must now compete, the pace of innovation and disruption is increasing at a remarkable rate. Facebook, founded in 2005 , has in excess of 1.5 billion users as of this writing - this would rank the social network among the world's largest nations. Proliferation of technology to this extent, and the permeation of it throughout the consumer process continues to change both the expectations of consumers, and the capabilities of organizations to fulfill these expectations.Disruption and innovation are not merely buzzwords in research any longer - these words and their underlying meanings are driving the business environment. Augmented by technology and enhanced by the speed with which information is produced and consumed, innovation and the ramifications of innovation on business decision making continue to be felt throughout the business community.

\section{Digital Disruption}

Intellectual property and capital drive valuations of organizations on a worldwide basis. Organizations such as Disney, Apple, and Coca-Cola derive large percentages of market capitalization, and this represents an opportunity for decision making within a disruptive innovation framework. It is important to also note and analyze the growing role and increasing influence that social media plays in the capital marketplace via stock valuation, market perception, and consumer feedback to management professionals (Lee, Hutton \& Shu, 2015). Disruption represents, in essence, an evolution of what organizations offer to the marketplace in anticipation of what end users will use and require. Decision making must be aligned with and embedded with a long term orientation keeping with the varied needs of organizational decision makers. Technology and effectively leveraging technology to better plan and anticipate the needs of shareholders and stakeholders provide an almost ideal roadmap for disruptive innovation to thrive and succeed.

Drilling specifically into disruptive innovation, key themes and attributes include taking advantage of information, especially market data, to better understand what consumers and clients are looking for in a product or service. Social media, derided by many as a time-wasting and productivity-draining endeavor, opens a window into what consumers are asking for in real time. Information generated directly from end users of products, in real time, creates a tremendous opportunity for linking short-term information and feedback to the strategic decision making process. A critical question, however, and one that faces virtually every organization and management team is how to best utilize the vast quantities of information generated. Additionally, and more important from a strategic planning perspective, is how management professionals should balance the information created in real time within a broader strategic framework.

\section{Disruptive Strategy in a Digital Environment}

Strategy is perceived as a master plan for the organization to follow through the next medium to long term period of time, but in an environment disrupted by a constant stream of information, this is an unsustainable approach. Strategy and strategic decision making must be updated continuously in light of new information received both from the marketplace as well as information received from internal operations and 
functional divisions. Marketing, which in a digitally driven business landscape, provides a potential two way street of communication between management and the market, must evolve alongside business decision making (Vien, 2015). Drilling down, marketing must take full advantage of the proliferation of technology and social media platforms, for both organizations and consumers, to increase points of contact and improve quality of feedback received from consumers and end users. Management professionals must adapt a perspective and mindset known as a strategic headset i.e., the organization and especially senior leadership must also continuously seek opportunities and information to improve both employees and the organization at large. Implementing such a mindset is imperative, and will require commitment on the part of both senior leadership and front-line employees. While every industry is unique, there are several themes that can be applied across industry lines.

First, an analysis of the broader business environment must be conducted in order to analyze and understand what major forces are influencing change within the competitive environment. Linking back to the concepts of Porter's 5 forces and Kaplan's balanced scorecard, it is evident that a wide variety of forces are contributing to the increasing rate of business disruption. Regulation, increased competition on a local and global scale, technology integration throughout the operational process, and communication between management teams and external parties (including customers, shareholders, and non-financial stakeholders) are driving changes in how organizations make decisions. Second, and focusing specifically on the influence of technology on strategic decision making, the flow of information within the organization provides insights. As business has increasingly grown global and multicultural in nature, the possibilities for internal creation and generation of ideas and new business opportunities have increased exponentially. Successfully implementing strategic thinking and business planning requires that management professionals successfully leverage the internal capabilities of employees within the entity.

Third, what skills will be necessary for the organization be competitive and successful in a digital and multifaceted business environment, and does the organization possess the appropriate capabilities to address these requirements? Similarly to how individual employees must be encourage to continuously update and expand existing skill sets, organizations and management professionals must embrace the technologies and processes that will drive business decision making in the coming years. Stated another way, the alignment of organizational resources and strategic objectives must be aligned to successful address the issues associated with executing strategic plans established by management (Patten, 2015). Facilitating an environment of innovation and strategic execution requires that decision makers have access to appropriate information in a timely and relevant manner. In order to link together short term and long term decision making, forming the foundation of successful strategic planning management decision makers must have access to the information necessary to enact longer term change.

Disruptive innovation, however, is not merely a combination of tools and information - it is a mindset that must permeate the organization. The information, technology, and tools that provide information to decision makers and employees throughout the organization, but the strategic headset requires that external communications are aligned with the overall strategic aims of the organization. Many organizations face the dual challenge of having to improve financial performance while also continuing to invest and grow for longer term opportunities, which can present a hurdle to long term thinking. In essence, this requires strategic plans to balance short and long term prerogatives. In order to anticipate and participate in disruptive trends and technologies influencing the market surrounding the organization, a broader perspective is required.

Disruptive innovation, virtually by default, requires that organizations have a marketwide view in order to foresee and effectively integrate disruptive forces into product and service development. This is perhaps best embodied in the mantra of fast failure that permeates many technology firms that dominate Silicon Valley and the broader technology environment. Creating an environment embodying the traits of disruption, innovation, and technological prowess is a complicated process. While several approaches are certainly available to companies, one in particular appears to offer several opportunities. It is important to keep in mind, throughout the discussion of strategic innovation, that continuing business operations must continue to function as usual and generate returns.

\section{Corporate Venturing And Strategic Thinking}

Managing innovation within an organization, especially the idea of disruptive innovation, is a very difficult task to accomplish within existing organizational structures with traditional hierarchy. Different functional groups and areas within organizations have different individual priorities, goals, objectives, and resources at management disposal. Additionally, and more important from a strategic planning and execution perspective is that different functional areas often have conflicting strategic objectives. This reality creates an additional layer of complexity that must be addressed in order to effectively execute strategic planning, especially disruptive innovation. Fueled by technology, and increases in information generated within the organization, an inherent contradiction quickly emerges within organizations seeking to disrupt internal 
operations. Even though capabilities and information have increased in speed, decision making in larger organizations often requires several layers of approval, which takes time that impedes the disruptive innovation methodology.

\section{Corporate Venturing}

Corporate venturing is a unique concept that may very well provide a possible solution to the inherent conflict between large organizational bureaucracy and approval processes, and the robust flexibility required for disruptive innovative thinking to thrive. Prior to drilling specifically into market examples of corporate venturing it is necessary to understand the framework within which such a concept is applicable. There are weaknesses readily evident with the concept of intrapreneurial innovation, i.e., that the larger corporate structure hamstrings the fundamentals of innovation (Barakat\&Parhizgar, 2015). Management professionals at larger organizations, seeing the pace of disruption, compounded by the onslaught of technology leveling the proverbial playing field, realize two facts.

First, innovation is a business necessity and must be incorporated into the strategic and operational planning process. This integration of innovation with other decision making processes is critical to embedding innovation within the broader decision making process. Second, and worryingly, is that many of the same structures that ensure compliance, efficiency, and operational execution hinder the rapid flexibility and adaptability required to disrupt and respond to market forces. Startup organizations, with smaller employee footprints and an explicit focus on innovation thinking, are better able to leverage technology and take advantage of opportunities.

Corporate venturing provides an almost ideal combination of financial backingand smaller organizational structure that underpins many successful innovative structures. In essence, what corporate venturing represents is almost an intersection of startup organizations and established organizations to help imbue the established entity with characteristics of innovative entities (Weiblen\&Chesbrough, 2015). Set up as spin-off entity from the larger parent organization, the entity established as part of the corporate venturing framework is usually only tasked with a single organizational goal. This goal is to disrupt the business operations of the larger organization, and to operate as if they were the competition for the larger entity. Several components are required to ensure that disruption actually occurs while also ensuring that financial discipline is still maintained, i.e., that investments are not made without a rigorous upfront review. Additionally, the corporate venturing project requires commitment and support of upper management, and should be assigned at least upper management sponsor. This, however, is merely the beginning of what is necessary for such an idea to produce desired results.

Corporate venturing, in essence, represents setting up an entirely new corporate structure; employees for the larger organization must be assigned and rotated between the larger parent company and the spin off entity (Garrett \&Covin, 2015). This rotation of employees in and out of the larger organization provides benefits that exceed the operational activities participated in while working at the spin off company. It is an opportunity, drilling down, for every employee participating with the program to work in and experience what a startup environment is like. This also presents an opportunity, to be led by upper management, to integrate strategic thinking into routine decision making. Once the objectives of the spin-off entity have been firmly established, employee participation and rotation has been discussed with middle management personnel, the time has arrived to actualize this theory. Before presenting an example of how a service organization could leverage such a strategy, there are several market examples that provide insights and applications that can be leveraged for use.

\section{Google Ventures\& Corporate Venturing}

Google, now a subsidiary of Alphabet, presents an almost ideal example of how corporate venturing can be and is utilized in the marketplace. The core business of Alphabet remains Google's search and advertising, but the leadership of the organization realized that it had the resources, data, and technological prowess to explore other potentially high-growth areas. Labeled moonshots in the context of Google, these opportunities were tangentially linked to core operations, but are able to leverage the financial and employee resources of the larger organization. In addition to developing internal organizations and moonshot-oriented projects, Alphabet (formerly Google) acquired several organizations to effectively leverage internal technological prowess. While many of these entities and projects do not generate headline news or financial results, two projects in particular stand out as generating tangible results.

Google Maps, the nearly ubiquitous global positioning based mapping and directional software, began as a moonshot project under the auspicious of Google Ventures. Including Google Capital, this branch of the larger organization funds and provides organizational support and structure to fund many moonshot projects including Google Maps. Self-driving cars, some of which feed information and data to improve the quality of Google Maps, are also a result of a moonshot entity that was supported, funded, and structured by the larger parent organization. Just looking at the examples of Google, and the success thatit has been able to achieve, it is 
apparent that market results are linked to the concept of corporate venturing. That said, while Google provides a high profile example of the potential benefits of corporate venturing, it is not the only organization able to achieve positive results.

\section{Corporate Venturing - Other Market Examples}

Corporate venturing is an increasingly popular tool for management teams and organizations seeking to expand product and service lines. Amazon has built an entire business model and strategic orientation around pursuing innovative thinking, new ideas, and new opportunities for product development. While some initiatives were initially unsuccessful, including the Amazon Fire phone, other such concepts (including the Kindle tablet) appear to be direct representations of disruptive innovation in action. Initially offered with fewer features and a smaller number of applications, the Kindle was marketed as a superior electronic reading device - capitalizing on the increased amount of text-based content consumed on mobile devices. Subsequent versions of the Kindle tablet feature improved functionality, expanded features, and a user experience rivaling that of higher-priced tablets including Samsung and Apple products.

Another high profile example of corporate venturing in the marketplace includes Tesla Motors. The entire organization, including the recently announced proposed purchase of Solar City, evokes the phrase -disruptive innovation. Led by Elon Musk, a co-founder of Paypal, the online payment firm, Tesla has successfully taken the concept of all electric vehicles and successfully constructed an auto market around this idea. Additionally, and truly representative of the concept of moonshot innovation, is the SpaceX initiative also led by Musk. Funded partially by Musk personally, and by the operations of Tesla, Space X is pioneering different methods of propelling rockets into orbit, as well as retrieving said rockets for multiple deployments.

\section{Corporate Venturing and Disruptive Innovation}

Drilling down specifically into disruptive innovation, and requirements that are necessary to successfully implement disruptive innovation within a corporate structure, many similarities exist when compared to corporate venturing. Of course, disruptive innovation and thinking requires the ability to react quickly both to internal and external forces, as well as the ability to make decisions in a real-time manner. Linking back to the theory of network effects and disruptive innovation, it is clear that the position of an organization within a business network represents a benchmark to judge the adaptability of the organization to disruptive innovation (Noyes, Brush, Hatten \& Smith-Doerr, 2014). Organizations such as Wal-Mart and Toyota provide market examples of how powerful such networks and network effects can be, and the financial returns achievable through such ventures.

Additionally, disruptive innovation requires that products and services, for all intents and purposes, be deployed to the marketplace as soon as these items as "good enough." Tweaks, updates, and improvements are also necessary when deploying new products and services, and disruptive innovation embraces this reality. Arguably, the most important connection between corporate venturing and disruptive innovation is the freedom from traditional decision making processes, and the ability to make decisions based on customer and client information. After reviewing the specifics of disruptive innovation, it is clear how closely linked the requirements of corporate venturing and disruptive innovation truly are. Flexibility, adaptability, and the importance of generating business decisions based in large part on consumer feedback, are critical elements of both approaches.

\section{Theory To Reality - Disruptive Innovation Through Corporate Venturing}

Corporate venturing appears to have been most widely adapted by technology or technology-based organizations, but the ideas of disruptive innovation can and should be implemented at a wide variety of organizations. As the global economy reorients toward an increasingly service-based approach, the importance of innovation and development of new products and services carries through to services, as well as productdependent companies. While not an exhaustive list or collection of recommendations, the scenario and information listed below are widely applicable to organizations seeking to embody disruptive innovation within existing decision-making processes.

\section{Disruptive Innovation - Strategy for a Digital Environment}

The first step toward embedding disruptive innovation into how business decisions are implemented is to familiarize personnel at all levels with both the theory and the reality of disruptive innovation. One possible approach that might make this more practical in a non-academic setting is to introduce the underlying concepts of disruptive innovation using market- based examples instead of relying exclusively on theory. Corporate venturing, which can leverage the positon of the organization with a network in addition to attracting flows of capital based on such a position, provides an opportunity for disruptive innovation to thrive in traditional organizations (Noyes, Brush, Hatten, Smith-Doerr, 2014). Examples, including those referenced throughout this 
writing, provide market examples of how such measures can be implemented at the specific organization. Second, and after introducing the idea of disruptive innovation throughout the organization, setting realistic but challenging innovation goals appears to represent an appropriate next level of implementation. This is where an opportunity for organizational learning and development can truly take place. Linking together operational metrics and driving forces, and the broader, longer term objectives embedded with disruptive innovation is important, and assists in building an environment conducive toward successful integration.

After establishing and initiating the conversation related to strategic thinking, and disruptive innovation as it pertains to the specific organization in question, the next logical step is to establish a vehicle to achieve change. Corporate venturing, outlined both in theory and with the market examples provided throughout this research piece, appears to represent a vehicle that can be utilized by a wide variety of organizations. Drilling in specifically into an example presents an opportunity to see how, from a high level point of view, about how a service organization can implement such a corporate structure can benefit the organization. While this example is presented from a high-level perspective, and every organization will clearly be different in terms of the specifics, this template and example can serve as an example for other organizations to follow.

\section{How To: Corporate Venturing and Disruptive Innovation}

A service organization competing within the higher education field is struggling to attract and expand the student body to finance the growth plans and objectives set by senior management. Traditional class room offerings, while performing well, are not growing fast enough, and first generation online programs do not seem to be attracting students at the same pace they had previously. Other traditional means of raising capital include fundraising, soliciting donations from alumni, and expanding into new geographic markets. That said, management professionals at the organization see this both as an opportunity and a challenge. This situation, in essence, provides an opportunity for the organization to actually implement and utilize some of the very business strategies that are taught and researched at the institution. Taken step by step, this checklist of questions and ideas are applicable to organizations seeking to spur innovation throughout the organization.

\section{Top Questions to Ask - Disruptive Innovation}

1. Which competitors in our industry are growing at a faster pace than we are, and what is driving that growth?

2. Are the competitive challenges that our entity faces unique to our organization, or are these structural forces that exist within the landscape at large?

3. What was our last most successful product or service launch?

4. Including feedback from consumer ratings agencies, better business organizations, social media feedback, and traditional survey tools, what is the sentiment of our organization within the marketplace?

5. What resources are available within the organization to establish an incubator or a spin-off entity to help foster an environment of innovation?

6. Do we, as a management team and professional leadership, have a strong enough grasp on what disruptive innovation is, or do we require further research?

7. Can we leverage technology to introduce new product and service offerings to our existing markets that take advantage of existing intellectual property and resources?

8. Are there opportunities for collaboration and coordination with other organizations that offer complementary products or services to ours?

9. Are the management professionals to be tasked with executing the incubator or spin-off entity familiar with both disruptive innovation and the long term objectives of the firm?

10. Can we start this today?

\section{Disrupting Business As Usual}

Disruptive innovation, of course, is a theory that can been received with both criticism and support from academia and market participants. Regardless of the strength and academic validity of any theory, however, the true test of an idea or concept is whether or not the theory can be successfully applied in the marketplace. Accounting professionals seeking to participate in this disruption must address the following in order to evolve from reporting experts to strategic risk advisors. Are key business drivers understood, in what context are resource allocation decisions finalized, and how can accounting practitioners play a larger role in the interpretation and distribution of strategically important information (Hancock \& Beasley, 2015)? In addition to disruption entering the everyday business conversation, the reality of the situation is that traditional business practices and methodologies are insufficient moving forward. Individual employees, from the top down, and organizations as a whole, must be willing to embrace continuous learning, question the status quo, and continuously seek new opportunities. Accelerated by the integration of technology throughout the business decision making process, the time between starting and organization, scaling that organization, and competing 
on an international scale is compressed even versus the early 2000s. While not an easy task, and change never is, disrupting and actively pushing the organization to explore new areas, opportunities, and ways to better deliver value to the marketplace is an absolute necessity. The tools, ideas, and market examples exist - it simply remains to management professionals to implement and execute these ideas within their organizations.

\section{References}

[1] Barakat, A., \&Parhizgar, K. D. (2015). The weakness of intrapreneurial and venture capitalist approaches to disruptive innovation: an opportunity for angle investors. Journal Of Competitiveness Studies, 23(4), 19-35.

[2] Garrett Jr., R. P., \&Covin, J. G. (2015). Internal corporate venture operations independence and performance: A knowledge-based perspective. Entrepreneurship: Theory \& Practice, 39(4), 763-790. doi:10.1111/etap.12059

[3] Gawer, A., \&Cusumano, M. A. (2014). Industry platforms and ecosystem innovation. Journal Of Product Innovation Management, 31(3), 417-433. doi:10.1111/jpim.12105

[4] Hamada T. (2014). Adaptation to technological innovation and corporate core-rigidities. International Journal Of Innovation Management, 18(2), -1. doi:10.1142/S1363919614500194

[5] Hancock, B. V., \& Beasley, M. S. (2015). Becoming a strategic risk adviser. Journal Of Accountancy, 219(2), 38-42.

[6] Laurell, C., \&Sandstrom, C. (2014). Disruption and social media - entrant eirms as institutional entrepreneurs. International Journal Of Innovation Management, 18(3), 1-17. doi:10.1142/S1363919614400064

[7] Lampikoski, T., Westerlund, M., Rajala, R., \&Möller, K. (2014). Green innovation games: Value-creation strategies for corporate sustainability. California Management Review, 57(1), 88-116. doi:10.1525/cmr.2014.57.1.88

[8] Lee, L. F., Hutton, A. P., \& Shu, S. (2015). The role of social media in the capital market: Evidence from consumer product recalls. Journal Of Accounting Research, 53(2), 367-404. doi:10.1111/1475-679X.12074

[9] Morio, J. (2014). Linking business intelligence to strategy. Financial Executive, 30(4), 66-69.

[10] Noyes, E., Brush, C., Hatten, K., \& Smith-Doerr, L. (2014). Firm network position and corporate venture capital investment. Journal Of Small Business Management, 52(4), 713-731. doi:10.1111/jsbm.12051

[11] Patten, L. (2015). The continued struggle with strategy execution. International Journal Of Business Management \& Economic Research, 6(5), 288-295.

[12] Schneider, S., \& Spieth, P. (2014). Business model innovation and strategic flexibility: insights from an experimental research design. International Journal Of Innovation Management, 18(6), -1. doi:10.1142/S136391961440009X

[13] Uggla, H. (2015). Aligning brand portfolio strategy with business strategy. IUP Journal Of Brand Management, 12(3), 7-17.

[14] Vien, C. L. (2015). The future of marketing: Thriving in a digital world. Journal Of Accountancy, 219(6), 1-4.

[15] Weiblen, T., \&Chesbrough, H. W. (2015). Engaging with startups to enhance corporate innovation. California Management Review, 57(2), 66-90. doi:10.1525/cmr.2015.57.2.66 